Péter Rebrus

UDK 811.511.141'342.41

Hungarian Academy of Sciences ${ }^{*}$

DOI: 10.4312/linguistica.56.1.239-252

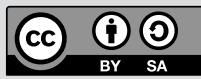

Miklós Törkenczy

Hungarian Academy of Sciences ${ }^{* *}$

\title{
TYPES AND DEGREES OF VOWEL NEUTRALITY
}

\section{INTRODUCTION}

Traditionally, the distinction between neutral and harmonic behaviour in vowel harmony has been considered a categorical property of (sets of) vowels, which uniquely identifies each vowel of a harmony system as a member of one of two non-overlapping sets, i.e., the set of harmonic vowels and the set of neutral vowels ${ }^{1}$ (e.g., van der Hulst and van de Weijer 1995). In this paper we focus on the ways in which neutrality is realised in suffixed forms and we argue that neutrality is not categorical. The graduality of neutrality has been discussed or suggested in the literature before (e.g., Anderson 1980) but has never been given a general explicit characterisation (as opposed to the degree of harmony, cf. Sanders and Harrison 2012; Alderete and Finley in press; also see section 3 for a discussion of the difference). We argue here that neutrality can manifest itself in different ways in different harmony systems since it derives from the ability of vowels to be involved in more than one pattern of neutrality, and a given pattern (i) may or may not be present in a system, (ii) may or may not combine with the other patterns, and (iii) may or may not be subject to variation - all of which influence the degree of neutrality. Based on this, we set up a scale of neutrality and offer a tentative quantification of the neutrality of harmony systems. We also show that in languages with more than one neutral vowel, the different neutral vowels may be of different types and degrees of neutrality. In the paper we only consider root/stem controlled front/back harmony systems with affix harmony where neutral vowels are phonetically front. ${ }^{2}$ For simplicity's sake, we identify affixes with suffixes (although everything we say about harmony in suffixes would apply to prefixes as well).

* rebrus@nytud.hu

** tork@nytud.hu

1 In some languages, a condition is added which permits the neutrality/harmonicity of a given vowel to be specific to some prosodic-position or morphological domain (Kiparsky and Pajusalu 2003). Here we abstract away from these positional or domain-specific differences in the harmonicity/neutrality of one and the same vowel.

2 This is typically the case in front/back harmony. 


\section{PATTERNS OF NEUTRALITY}

In a harmonic system, vowels are biased to co-occur in such a way that they agree in the value of a designated feature (the harmonic feature) within a morphologically and/ or phonologically circumscribed domain. In a harmony system, vowel neutrality can be identified as the lack of such bias. This can manifest itself in three different ways: (a) a suffixal neutral vowel is unbiased as a 'target' in that it can systematically co-occur with vowels (potential triggers in the stem) of either harmonic value: this pattern of neutrality occurs when a stem is affixed with an invariant suffix. A neutral vowel in a root or a suffix is unbiased as a "trigger" in that (b) it does not modify the harmonic bias imposed on the target by other harmonic sources: this pattern of neutrality consists in transparency to the propagation of harmonic features; and (c) it does not impose its own harmony requirement on other vowels: this pattern of neutrality is anti-harmony requiring suffixation with suffix alternants that have a harmonic value opposite to that of the neutral vowel. ${ }^{3}$ These possibilities ${ }^{4}$ are summarised in Figure (1) below for front/back harmony, where neutral vowels are phonetically front (henceforward, we employ the following abbreviations and conventions: $\mathrm{B} / \mathrm{F} / \mathrm{N}$ : back/front/neutral vowels; [ ]: stem boundaries; consonants are left unindicated in formulaic descriptions, e.g., $\mathrm{BN}=\mathrm{C}_{0} \mathrm{BC}_{0} \mathrm{NC}_{0}$ ).

\section{(1) Patterns of neutrality}

\begin{tabular}{|l|l|l|}
\hline $\mathrm{N}$ is unbiased as a: & name of the pattern & in formula \\
\hline a. target & invariant suffixes $(\mathrm{IV})$ & $[[\mathrm{B}] \mathrm{N}] \&[\mathrm{~F}] \mathrm{N}]]$ \\
\hline b. trigger wrt. to another source & transparency $(\mathrm{TP})$ & {$[[\mathrm{BN}] \mathrm{B}] \&[[\mathrm{FN}] \mathrm{F}]$} \\
\hline c. trigger as a source & anti-harmony $(\mathrm{AH})$ & {$[[\mathrm{N}] \mathrm{B}]$} \\
\hline
\end{tabular}

The patterns (1a-b) above involve both harmonic values: (a) invariant suffixes necessarily occur after both front and back stems, and (b) transparency typically consists in the neutral vowel's lack of bias while passing on both the front and the back bias of the preceding harmonic vowel. ${ }^{5}$ Anti-harmony (1c), however, only involves a harmonic

3 A reviewer points out that lack of harmony (presumably in the form of hesitation) could in principle be the realization of a neutral vowel's lack of bias as a trigger. This is a valid point, but, interestingly, this state of affairs seems to be unattested, cf. Aoki (1968). Note that our use of the term antiharmony is different from Sanders and Harrison (2012), who use it to refer to preference for disharmony globally in a system.

4 Another possible (and attested) pattern of neutrality is one that is completely contained within the monomorphemic form. This is the "mixed" root pattern where the neutral/unbiased character of a vowel manifests itself in its ability to freely co-occur with any other vowel of the system within a root. We disregard this pattern in this paper since we are focusing on neutrality in affix harmony. For a discussion of mixed stems in Hungarian and their relevance to neutrality, cf. Törkenczy (2011) and Törkenczy et al. (2013).

5 It is a definitive property of the IV neutrality pattern (1a) that an allomorph with the same vowel occurs after both front harmonic and back harmonic stems (this is indicated by the symbol "\&" in 
value in the suffix which is the opposite of the phonetic value of the (neutral vowel-) stem, i.e., $[[\mathrm{N}] \mathrm{B}]$, but not necessarily $[[\mathrm{N}] \mathrm{F}]{ }^{6}$

\section{TYPOLOGY}

Each of the patterns in (1) may be present in or absent from a given harmony system (cf. Kiparsky and Pajusalu 2003). ${ }^{7}$ Thus, neutrality can manifest itself in more than one way and the different patterns may or may not co-occur in a given system. Therefore, it is possible to define degrees of neutrality and set up a classification of systems ${ }^{8}$ according to the types of neutrality they permit. Naturally, other classifications are also possible, e.g., ones that are based on a measure of harmony assessed "globally" in a system. Some recent proposals (Sanders and Harrison 2012; Alderete and Finley in press) measure the degree of global (dis)harmony of a system independently of any specific neutrality pattern (such as transparency/opacity, antiharmony etc.). In our approach the degree of neutrality of a (sub)system depends on the "strength" of the neutrality patterns (IV, TP and AH) measured in relative word-type frequency (the type frequency of word-forms (not lemmas or tokens)). This is different from these global approaches, which characterise systems by measuring the degree of global (dis)harmony in wordtypes (Sanders and Harrison 2012) or stem-types (Alderete and Finley in press) within a system. A crucial difference is that disharmony (co-occurring vowels that disagree in their specifications for the harmonic feature) is not the same as the neutrality defined in this paper (involvement of a vowel in (some of) the neutrality patterns IV, TP, AH) because (a) a neutrality pattern does not necessarily result in disharmony (antiharmony $[[\mathrm{N}] \mathrm{B}]$ is always disharmonic but the other neutrality patterns are not necessarily so, e.g., in TP, transparency to backness is disharmonic, [[BN]B], but transparency to frontness is not $[[\mathrm{FN}] \mathrm{F}]$ ), and (b) disharmony is not necessarily associated with the neutrality patterns we examine here (e.g., root-internal $[\mathrm{NB}]$ is disharmonic, but does not realise IV, TP or $\mathrm{AH}$ ).

the relevant formula in the rightmost column). However, in the TP neutrality pattern (1b), transparency to the frontness of a trigger vowel and transparency to the backness of a trigger vowel are logically independent and may be assessed independently. Indeed, according to Kiparsky and Pajusalu (2003), there is a rare type of harmony system in which transparency to backness occurs but transparency to frontness does not ([[BN]B] \& [[FN]B] ), while "anti-transparency" ([[BN]F] $\&[[\mathrm{FN}] \mathrm{B}])$ is unattested in harmony systems. For the sake of simplicity, we do not distinguish these two kinds of transparency in this paper, and pattern (1b) covers both: [[BN]B] \& [[FN]F].

6 This also means that in a system with total anti-harmony, all stems with a neutral vowel "trigger" behave like $[[\mathrm{N}] \mathrm{B}]$ and no stems behave like $[[\mathrm{N}] \mathrm{F}]$. Practically, most anti-harmonic systems show both; see section 4 for variation in $\mathrm{AH}$.

7 Although they cannot combine arbitrarily, see Kiparsky and Pajusalu (2003). AH entails TP for backness. There is no similar constraint on the occurrence of invariant suffixes, so theoretically IV can combine freely with the two other patterns of neutrality. In this section we examine only those systems where neutrality involves invariant suffixes (i.e., TP entails IV), but in section 4 the Hungarian examples involve variation for all the three patterns, including IV.

8 Or subsystems; see section 5. 
In table (2) below we show four language types (2o-iii), which exhibit different types of neutrality of Ns occurring in a harmony system. Since we have defined neutrality as the lack of bias, the different properties of the patterns (1a-b) vs. (1c) discussed above affect the degree of neutrality of a system differently. The presence of IV and/ or TP truly means a lack of bias since a neutral vowel can occur after a vowel of either harmonic value (IV) and a vowel of either harmonic value can occur after a neutral vowel (TP). By contrast, total AH in a system is a kind of bias because only B can occur after $\mathrm{N}$ in a suffix. Therefore, none of the language types (2o-iii) in (2) have maximal neutrality, because neither the ones without AH (2o-ii), nor the ones with AH (2iii) have 'ideal' neutral properties, i.e., a complete lack of bias in this respect.

(2) Some language types based on neutrality patterns (1a-c)

\begin{tabular}{|l|c|c|c|c|}
\hline \multicolumn{1}{|c|}{ language types - examples } & a. IV & b. TP & c. AH & $\begin{array}{c}\text { neutrality } \\
\text { (lack of bias) }\end{array}$ \\
\hline o. no neutral vowel - Turkish & - & - & - & no \\
\hline i. only IV, no TP/AH - E Khanty /i/ & + & - & - & low \\
\hline ii. IV \& TP, no AH - Finnish /i/, /e/ & + & + & - & high \\
\hline iii. IV \& TP \& AH - Uyghur /i/, /e/ & + & + & + & high \\
\hline
\end{tabular}

Note that (2) is a descriptive kind of typology rather than a "factorial" one. It shows a sample of the possible types of harmony systems representing various degrees of neutrality rather than limiting what is a possible system with (or without) neutrality; e.g., a (front/back) system with AH but without TP does not occur to the best of our knowledge and is arguably impossible (cf. Kiparsky and Pajusalu 2003; Rebrus and Törkenczy 2015). ${ }^{9}$ Nevertheless, it could be added to Table 2 where it would represent a system of intermediate neutrality just like (2ii) or (2iii), which are attested.

\section{VARIATION}

Patterns (1a-c) may be subject to variation: ${ }^{10}$ (a) a given vowel may occur in both invariant and harmonically alternating suffixes in a system, (b) transparency-opacity may be variable $[[\mathrm{BN}] \mathrm{B} / \mathrm{F}]$, and/or (c) anti-harmony may be variable $[[\mathrm{N}] \mathrm{B} / \mathrm{F}]$. This yields further language types, possibly of different degrees of neutrality. As an example, consider a harmony system with invariant neutral vowel suffixes (both [[B]N] and $[[\mathrm{F}] \mathrm{N}]$ occur), variable transparency (both $[[\mathrm{BN}] \mathrm{B}]$ and $[[\mathrm{BN}] \mathrm{F}]$ (and also $[[\mathrm{FN}]$

9 See Rebrus and Törkenczy (2015ab) for a discussion and a principled explanation that attributes the restrictions on patterns to monotonicity.

10 Here we do not distinguish between lexical variation and vacillation and use the symbol "/" to denote variation (of either kind), see Rebrus and Törkenczy 2015b. 
F]) occur), and without antiharmony ([[N]B] does not occur). Such a system (see 3ii' below) would be somewhere between $(3 \mathrm{i}=2 \mathrm{i})$ and ( $3 \mathrm{ii}=2 \mathrm{ii})$ in the tentative scale in (2) because here $\mathrm{N}$ does have some bias in transparency since $[[\mathrm{BN}] \mathrm{F}]$ also occurs with some probability (indicated by “+/-" in (3)). A system with variable IV (in which there is lexical variation such that some $\mathrm{N}$-vowel suffixes are invariable while others alternate harmonically) but without TP or AH is even less neutral than the invariable system in ( $3 \mathrm{i}=2 \mathrm{i})$ because in such a system, some suffixes with $\mathrm{N}$ are targets of harmony. A system of maximal neutrality (3iii' below) has (in addition to invariant suffixes and invariable transparency) variable antiharmony since in this case the neutral vowel of an all-neutral root imposes no bias at all on the suffix (i.e., both B and F can occur in the suffix $\left.{ }^{11}\right)$. An approximate neutrality scale of harmony types that includes these variable systems as well is shown in (3).

(3) Degrees of neutrality in types of harmony systems with and without variation

\begin{tabular}{|l|c|c|c|c|}
\hline \multicolumn{1}{|c|}{ language types } & a. IV & b. TP & c. AH & neutrality \\
\hline o. $\quad$ no neutral vowel & - & - & - & no \\
\hline i’. variable IV, no TP/AH & $+/-$ & - & - & very low \\
\hline i. $\quad$ only IV, no TP/AH & + & - & - & low \\
\hline ii’. IV, variable TP, no AH & + & $+/-$ & - & intermediate \\
\hline ii. IV \& TP, no AH & + & + & - & high \\
\hline iii. IV \& TP \& AH & + & + & + & high \\
\hline iii'. IV \& TP \& variable AH & + & + & $+/-$ & maximal \\
\hline
\end{tabular}

\section{GRADUALITY}

More than one neutral vowel occurs in some harmony systems. In such a system neutrality may be homogeneous, i.e., all neutral vowels behave the same way: this is the case of /i/ and /e/ in Finnish and Uyghur (cf. Anderson 1980; Vaux 2000) - see (2ii,iii); or it can be non-homogeneous when the different neutral vowels show different degrees of neutrality because they are involved in the patterns (3i'-iii') differently. We consider languages of this kind polysystemic, i.e., they contain vowel harmony subsystems of more than one type such that the different types are specific to different (groups of) neutral vowels. Front/back harmony in Hungarian is an example where this is referred to as the height effect (e.g., Hayes and Cziráky Londe 2006), which means that the higher a front unrounded vowel is, the more neutrally it behaves. This is illustrated in (4) below, where rows contain the different Hungarian front unrounded vowels /i i: e: $\varepsilon /$ and the columns show the patterns of neutrality. With the exception of $/ \mathrm{i}$ / all the neutral vowels in Hungarian show variation in IV in addition to variation in TP and/or AH (we discuss the Hungarian data in more detail below).

11 Assuming that they both occur with the same probability. 
(4) Hungarian: differences in the neutrality of neutral vowels

\begin{tabular}{|c|c|c|c|c|}
\hline language types & a. IV & b. TP & c. $\mathrm{AH}$ & neutrality \\
\hline ii'. variable IV/TP, no AH - Hungarian / $\varepsilon /$ & $+/-$ & $+/-$ & - & low \\
\hline iii'"'. variable IV/TP/AH - Hungarian /e:/ & $+/-$ & $+/-$ & $+/-$ & intermediate \\
\hline iii'”. TP \& variable IV/AH - Hungarian /i/ & $+/-$ & + & $+/-$ & high \\
\hline iii'. IV \& TP, variable AH - Hungarian /i:/ & + & + & $+/-$ & maximal \\
\hline
\end{tabular}

Note that - while the systems in the sample of possible types shown in (3i'-iii') can be naturally and uniquely arranged along a scale of neutrality ranging from minimally neutral to maximally neutral - it is not possible to arrange all the theoretically possible types in a similar scale. For instance, it is not possible to determine if a system with variable IV and invariable TP $(<+/-,+,->)$ is more or less neutral than its "mirror image", i.e., a system with invariable IV and variable TP $(<+,+/-,->)$. Similarly, it is not possible to determine the difference in neutrality between (3i) $<+,-,->$ and (4ii') $<+/-,+/-,->.{ }^{12}$ This in itself is a motivation for characterizing or calculating the neutrality of a vowel with a value whose assignment is consistent across all vowels.

We present here a tentative quantification of the neutrality of Hungarian vowels which fall into several types based on their behaviour in the Hungarian front/back harmony system (summarised in (5)). The numbers in (5) below and in the text indicate the approximate degree of neutrality on a 5-point scale from [0] to [4] ([0]=non-neutral, [4]=totally neutral, $[1,2,3]=$ =variably neutral) depending on their involvement in the three patterns of neutrality (IV, TP and AH) that occur in the Hungarian system. It must be pointed out here that there is no theoretical reason why neutrality should be assessed on a 5-point scale rather than a scale of fewer or more than five degrees of neutrality; the motivation is practical: qualitatively, 5 degrees of neutrality behaviour characterise the Hungarian system. The vowels traditionally considered as neutral $/ i$, i., e., $\varepsilon /{ }^{13}$ are involved in these neutrality patterns in the following way.

(a) Occurrence in invariant suffixes: long /i:/ only occurs in invariant suffixes (e.g., verb-forming -iit, ton-i:t 'teach') and is therefore completely neutral in this respect [4]; short /i/ mostly occurs in invariant suffixes (e.g., Terminative -ig, ha:z-ig 'up to the house') but it does occur in an alternating one (Pres.Sg3.Def $-\mathbf{i} \sim \mathbf{j} \mathbf{p}, \mathbf{d o b}$-jp 'throw', yt-i 'hit'); invariant : alternating ratio $=11: 1$, so it is less neutral [3]. /e:/ is frequent in

12 This is not true of the Hungarian data shown in (4), which, again, represent a subset of the possible types and happen to be such that they can be arranged in a scale of neutrality in a natural and unique way, as shown in the last column of (4). The reason is that in this sample it is never the case that a given vowel $\mathrm{V}_{\alpha}$ is more neutral than another $\mathrm{V}_{\beta}$ with respect to one pattern of neutrality while $\mathrm{V}_{\beta}$ is more neutral than $\mathrm{V}_{\alpha}$ with respect to another pattern.

13 The neutrality of $/ \mathcal{E} /$ has been debated in the literature of Hungarian vowel harmony (see Törkenczy 2011 for an overview) but / $/$ / can be given comfortable place as soon as we abandon the view that the distinction between neutral and non-neutral is categorical (which is our view here and see also Hayes and Cziráky Londe 2006). 
both invariant suffixes (e.g., Causal -errt, ha:z-errt 'for the house') and alternating suffixes (e.g., Adessive -ne:l na:l, kert-ne:l 'at the garden', ha:z-na:l 'at the house'); invariant : alternating $=7: 10^{14}$, and thus it is less neutral than $/ \mathrm{i} /[2]$. $/ \varepsilon /$ is frequent in alternating suffixes (e.g., Inessive -ben $\sim$ bon, kert-ben 'in the garden', ha:z-bon 'in the house'), but it occurs in invariant ones only in a handful of special diminutive constructions (i.e., Diminutive - $\mathbf{\varepsilon s , ~ k p r - \varepsilon s ~ ' C h a r l e y ' ) ; ~ i n v a r i a n t ~ : ~ a l t e r n a t i n g = 2 : 5 0 , ~ s o ~ i t ~ i s ~}$ even less neutral [1].

(b) Variability in transparency: /i, i:/ are always transparent in all roots (e.g., kotfinok/*koti-nek 'car-DAT', pppirr-nok/*pppirr-nek 'paper-DAT'); thus, they are completely neutral [4] in this respect. /e:/ is usually transparent with some root-specific lexical variation (invariable back-suffixed [Be:] stems e.g., karve:-nok/*kaive:-nek 'coffee-DAT' are much more frequent than variably suffixed [Be:] stems e.g., przernnok/prze:n-nek 'arsenic-DAT'): thus, it is less neutral than /i, i:/ [3]. / $/$ / shows a high degree of lexical variation and vacillation (variable suffixation, e.g., hotel-nok/hotelnek 'hotel-DAT', is more frequent than invariable front suffixation, e.g., kontsert$\mathbf{n} \boldsymbol{\varepsilon} \mathbf{k} /{ }^{*}$ kontsert-nok 'concert-DAT' or mostly invariable back suffixation, e.g., mpsek$\mathbf{n o k} / * \mathbf{m o s} \varepsilon \mathbf{k}-\mathbf{n} \varepsilon \mathbf{k}$ 'self-employed-DAT': thus, it is weakly neutral in this respect: [2].

(c) Antiharmony: /i, i:/ frequently occur in anti-harmonic stems and almost all antiharmonic stems have these vowels; therefore, they are highly neutral [4] in this respect. The vowel /e:/ very rarely occurs in antiharmonic stems (there are only two antiharmonic free stems and a few bound stems with /e:/, thus: [2]), and /E/ practically does not, hence [0]. Table (5) shows these values for all the front vowels in Hungarian. We have also included front rounded vowels, which are non-neutral (i.e., they only occur in harmonically alternating suffixes, they are invariably opaque and do not occur in antiharmonic roots), to facilitate comparison with the neutral ones.

In the last column, we have given the average scores of the vowels in points and converted to percentages where $100 \%$ means complete neutrality and $0 \%$ means the total lack of neutrality (fully harmonic behaviour). These values represent the neutrality scores of the vowels. It can be seen in (5) that the neutrality scores of the vowels that are traditionally considered neutral fall within a rather wide range: from a $100 \%$ neutral /i:/ through "half-neutral" /e:/ (58\%) down to the least neutral/e/ (25\%).

14 Stem final a and $\varepsilon$ lengthen to a: and e:, respectively, before suffixes by the productive process of Low Vowel Lengthening (see e.g., Siptár and Törkenczy 2000). This also affects suffixes that are $\varepsilon$-final when word-final, e.g., the possessive suffix -(j)a/ $\boldsymbol{\varepsilon}$ - compare fyl- $\underline{\varepsilon}$ 'ear-POSS.3SG' and fyl-e-t 'tear-POSS.3SG-ACC'. If we also include these suffixes, then the invariant-alternating ratio changes to $7: 13$. 
(5) Tentative estimation of the degree of neutrality for front vowels in H. (5-point scale: $0, \ldots, 4)$

\begin{tabular}{|l|c|c|c|c|}
\hline \multicolumn{1}{|c|}{ front vowels } & a. IV & b. TP & c. AH & $\begin{array}{c}\text { average } \\
\text { (neutrality score) }\end{array}$ \\
\hline high i: (= totally neutral) & 4 & 4 & 4 & $4.0(100 \%)$ \\
\hline high i & 3 & 4 & 4 & $3.7(92 \%)$ \\
\hline high-mid e: & 2 & 3 & 2 & $2.3(58 \%)$ \\
\hline low-mid $\varepsilon$ & 1 & 2 & 0 & $1.0(25 \%)$ \\
\hline round y y: ø ø: (= non-neutral) & 0 & 0 & 0 & $0.0(0 \%)$ \\
\hline
\end{tabular}

Note that the numbers in each of the columns ( $5 \mathrm{abc})$ decrease ${ }^{15}$ from top to bottom; thus, (5a), (5b) and (5c) each yield the same scale independently as the scale in the last column, which means that the height effect manifests itself in all the three patterns of neutrality. This is not a theoretical necessity, but a property of the Hungarian system, which is a sample of the theoretically possible types (it is possible to have a decreasing average score of neutrality while some of the patterns of neutrality do not show a decreasing scale).

The main problem with the quantification is that the scores for each of the neutrality patterns are given "impressionistically" and therefore a five-point equidistant scale $[0,1,2,3,4]$ is not entirely justified. For instance, there is no reason why the difference between the TP of /i, i:/ [4] and the TP of /e:/ [3] should be identical with the difference between the TP of /e:/ [3] and the TP of /E/ [2]. Also nothing guarantees that the "intermediate" degrees truly mean the same across patterns, i.e., for example /e:/ is truly equally neutral with respect to IV and AH (both of its scores are [2]).

A more realistic way of quantifying vowel neutrality is based on the frequency ratios of items realising these patterns. In order to develop such a quantification we have carried out a corpus study in Hungarian where we have made the following measurements and calculations for a frequency-based quantification of neutrality. We have used the Szószablya web corpus of the Hungarian language (Halácsy et al. 2004), which contains 541 million word tokens and 2.32 million word types.

We have calculated the TP neutrality ratio of the 4 neutral vowels in the following way: in each of the four classes of disyllabic [BN]-type stems, which differ in the neutral vowel ([Bi:], [Bi], [Be:], [Be]) we have counted how many of the harmonically suffixed word-types contain a front suffix alternant ([[BN]F]) and how many of them contain a back suffix alternant $([[\mathrm{BN}] \mathrm{B}]) \cdot{ }^{16}$ Then, we have calculated the percentage of the back-suffixed word-types compared to the number of all the word types (F-suffixed and B-suffixed) in the given class, i.e., the following "backness" ratio:

15 In a weak sense that permits identical adjacent values.

16 We have counted types and not tokens - we do not consider how many tokens of a word type are found in the corpus, e.g., the types fotelbpn and fotelben 'armchair-in.' are both found in the corpus, but in our calculations it does not matter that the former is found 374 times and the latter 376 times since each type counts once. 


$$
p_{\mathrm{TP}}=\frac{\text { freq }([[\mathrm{BN}] \mathrm{B}])}{\text { freq }([[\mathrm{BN}] \mathrm{B}])+\text { freq }([[\mathrm{BN}] \mathrm{F}])}
$$

In the case transparency, $p$ defined above is used for the degree of neutrality. If it is $100 \%$, then only B-suffixed word-types occur, showing that transparency (TP) is maximal, which means that the neutral vowel examined is completely neutral with respect to TP. It can be seen in column (b) in (8) below that /i:, i/ are maximally neutral ( $p=100 \%)$ and /e:/ is near-maximally neutral $(p=96.8 \%)$ in this respect. Although opacity is more frequent than transparency in the case of $/ \varepsilon /, / \varepsilon /$ behaves transparently in a quarter of the word-types $(p=25.3 \%)$.

In order to quantify neutrality in antiharmony, we have examined the same relative frequencies of word-types, but this time those that containing monosyllabic $[\mathrm{N}]$ stems with the four neutral vowels [i:], [i], [e:], [ع]. Then we have converted the resulting backness ratios (a number between $0 \%$ and $100 \%$ ), so that a backness ratio of exactly $50 \%$ (a hypothetical type of variation in which front and back suffixed word types occur with equal probability) corresponds to $100 \%$ neutrality and a backness ratio of $100 \%$ or $0 \%$ (no variation: complete antiharmony and complete lack of antiharmony, respectively) corresponds to $0 \%$ neutrality. We get the neutrality degree $p$ in $\mathrm{AH}$ by taking the distance of a relative word type frequency (backness ratio) from 50\% (the theoretical maximum of neutrality in AH), multiply it by two and calculate the distance of this number from $100 \%$, as shown in (7), where $r_{\mathrm{AH}}$ is the backness ratio and $p_{\mathrm{AH}}$ is the degree of neutrality:

$$
r_{\mathrm{AH}}=\frac{\operatorname{freq}([[\mathrm{N}] \mathrm{B}])}{\text { freq }([[\mathrm{N}] \mathrm{B}])+\operatorname{freq}([[\mathrm{N}] \mathrm{F}])} \quad p_{\mathrm{AH}}=1-2 \cdot\left|0.5-r_{\mathrm{AH}}\right|
$$

The relative word-type frequencies (backness ratios $r_{\mathrm{AH}}$ ) are the following: /i:/: $51.8 \%$, /i/: $10.4 \%$, /e:/: $2.1 \%$, and $/ \varepsilon /: 0.0 \%$. The figures show that the number of harmonic and antiharmonic word-types with a long /i:/ in the monosyllabic root is approximately the same (in fact there are slightly more antiharmonic types than harmonic ones), and thus the neutrality of /i:/ with respect to antiharmony is close to the theoretical maximum ( $p=96.4 \%$ ). The relative word-type frequency is much lower for $/ \mathrm{i} /$ $(10.4 \%)$, i.e., only one word type with a root internal short $/ \mathrm{i} /$ out of ten is antiharmonic; therefore, the neutrality of $/ \mathrm{i} /$ is low $(p=20.8 \%)$. The antiharmonicity values (expressed in backness ratios) of /e:/ and $/ \varepsilon /$ are even lower, $2.1 \%$ and $0 \%$, respectively, which corresponds to very low neutrality ratings with respect to antiharmony: $p=4.2 \%$ and $p=0.0 \%$, respectively. This is shown in (8c).

Finally, consider the neutrality ratings with respect to invariance in suffixes. Here we have calculated the neutrality values using the statistics about the distribution of vowels in alternating and invariant suffixes given in the discussion of table (5) above. The neutrality rating of a neutral vowel with respect to invariance is the ratio of invariant (i.e., harmonically non-alternating) suffixes containing the given neutral vowel to all the suffixes (invariant or harmonically alternating) that contain it. This is shown 
in (8a). All the suffixes that have long /i:/ are invariant, so it is maximally neutral with respect to invariance ( $p=100 \%$ ). There is only one alternating suffix with short $/ \mathrm{i} /$ while all the others are invariant $(p=91.7 \%)$. The other neutral vowels /e:/ and $/ \varepsilon /$ are considerably less neutral with respect to invariance: only about a third of the suffixes with /e:/ are invariant $(p=35.0 \%)$ and only two suffixes with $/ \varepsilon$ / are invariant while a great majority of them alternate $(p=3.8 \%)$.

(8) Neutrality scores (in percentage) calculated from type frequency ratios

\begin{tabular}{|l|c|c|c|c|c|}
\hline \multirow{2}{*}{ front unrounded vowels } & \multirow{2}{*}{ a. IV } & \multirow{2}{*}{ b. TP } & \multirow{2}{*}{ c. AH } & \multicolumn{2}{|c|}{ average (neutrality score) } \\
\cline { 5 - 6 } & & & & by frequency & in (5) \\
\hline high i: & 100 & 100 & 96.4 & $\mathbf{9 8 . 8}$ & 100 \\
\hline high i & 91.7 & 100 & 20.8 & $\mathbf{7 0 . 8}$ & 92 \\
\hline high-mid e: & 35.0 & 96.8 & 4.2 & $\mathbf{4 5 . 3}$ & 58 \\
\hline low-mid $\varepsilon$ & 3.8 & 25.3 & 0.0 & $\mathbf{9 . 7}$ & 25 \\
\hline
\end{tabular}

\section{CONCLUSION}

As a conclusion let us examine what our study shows about (i) the relationship between the neutrality scores of the different vowels in a given pattern and on the average, and (ii) the relationship between the neutrality scores of one and the same vowel in the different neutrality patterns $(a, b, c)$.

(i) The average neutrality scores of the neutral vowels are higher in (5) than in (8). This is due to the fact that the impressionistic five-point scale (5) is based on is not fine-grained enough. Nevertheless, the tendency of the scores in (5) and (8) is the same, i.e., they arrange the four neutral vowels in the same hierarchy of neutrality. The same relationship holds true of the average frequency-based neutrality scores of (8) (and (5)), and also of the scores of the vowels on the individual neutrality patterns, i.e., the neutrality scores decrease in each of the columns ( $8 \mathrm{abc})$. This confirms the general view about the neutrality differences between the Hungarian neutral vowels (the height effect), which is typically either simply stipulated in studies (Siptár and Törkenczy 2000) or based on a single neutrality pattern, TP (Ringen and Kontra 1989; Hayes and Cziráky Londe 2006). It has been claimed in the literature that the height effect, i.e., the correlation between the increase of openness of a phonetically front neutral vowel and the decrease of neutrality is natural cross-linguistically (e.g., Anderson 1980; Kiparsky and Pajusalu 2003) and even phonetically motivated (in TP e.g., Beňuš 2005; Beňuš and Gafos 2007).

(ii) It can be seen in (8) that relationship between the neutrality scores for the three neutrality patterns is such that for every neutral vowel the neutrality score in transparency is always higher than the score in antiharmony and the score in invariance is always between transparency and antiharmony: 


$$
p_{\mathrm{TP}} \geq p_{\mathrm{IV}} \geq p_{\mathrm{AH}}
$$

This is graphically represented in Figure 1 below:

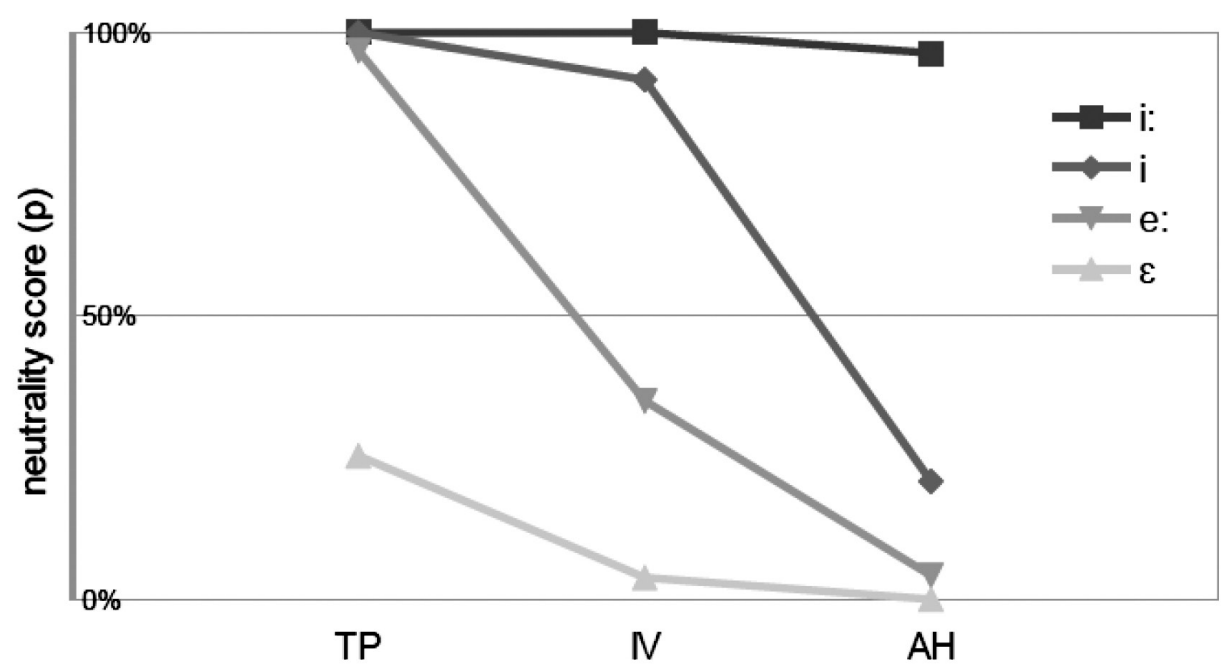

Figure 1. Neutrality score of different vowels by different patterns

It is reasonable to ask if this relationship in (9) (a) is just a parochial fact about the patterns Hungarian neutral vowels are involved in or one that holds universally/crosslinguistically, or (b) whether it has some explanation/motivation. Unfortunately, at the present state of our knowledge neither question can be given a clear answer. First, we know from studies of front/back harmony systems (cf. Kiparsky and Pajusalu 2003; Rebrus and Törkenczy 2015a) that the presence of AH in a system implies the presence of TP and that this can be generalised to variable TP and variable AH: the backness ratio of TP must be higher than the backness ratio of AH. This follows form the general (universal) principle of monotonicity that constrains (front/back) harmony systems (cf. Rebrus and Törkenczy 2015ab). However, the fact that $r_{\mathrm{TP}} \geq r_{\mathrm{AH}}$ holds generally for backness ratios does not necessarily mean that $p_{\mathrm{TP}} \geq p_{\mathrm{AH}}$ holds for neutrality scores as well, since the interpretation of neutrality (the relationship between a backness ratio and the corresponding neutrality score) is different for TP and AH (see sections 3 and 5 above). The placement of IV in between TP and AH universally is even more uncertain since we know less about it cross-linguistically: the available studies typically assume that it exists in the systems in which they examine TP (and possibly AH). ${ }^{17} \mathrm{As}$

17 We know that there are systems in which harmony is limited to the root (e.g., Marash dialect of Armenian, cf. Vaux 1998). Trivially, in such a system, all affixes are invariant, thus there are systems with IV, but without TP and AH. However, these systems are irrelevant for us here since we are only interested in systems in which TP and $\mathrm{AH}$, both of which manifest themselves in affix alternations, could in principle occur. 
for question (b), i.e., the explanation/motivation of (9), we can look at the problem in two ways. On the one hand one could look at the trigger for potential disharmony and argue that in front/back harmony the occurrence of a harmonic value B is motivated in the environment of another B even if it is not strictly adjacent: BNB (as in TP), but it is not otherwise: NB (as in AH) or BN (as in IV). Therefore, it is to be expected that TP should be more frequent than AH or IV. This view groups TP (motivated) vs. AH, IV (unmotivated). On the other hand, it is also possible to look at potential disharmony as a function of the target. In the case of IV disharmony is motivated since by definition the suffix is invariably $\mathrm{N}$, thus it cannot change since it does not alternate. By contrast, in TP and AH, disharmony is not motivated in this sense since the suffix is an alternating one and it could harmonise. Thus, one would expect IV to be more frequent than TP or AH. This view groups IV (motivated) vs. TP, AH, (unmotivated). A combination of the two views establishes $\mathrm{AH}$ as the least frequent, but does not determine a relationship between TP and IV. It must be noted that, again, this argument is about relative frequencies (backness ratios) rather than neutrality scores and thus, for the same reason as discussed above, does not really explain the relationship in (9).

This work has been supported by National Scientific Grant OTKA-104897 'Variation in Phonology'. We would like to thank the anonymous reviewer for drawing our attention to recent relevant literature.

\section{References}

ALDERETE, John/Sarah FINLEY (in press) "Gradient vowel harmony in Oceanic." To appear in Language and Linguistics 17.

AOKI, Haruo (1968) “Toward a Typology of Vowel Harmony.” International Journal of American Linguistics 34, 142-145.

ANDERSON, L. (1980) "Using asymmetrical and gradient data in the study of vowel harmony." In: R. Vago (ed.), Issues in Vowel Harmony. Amsterdam: John Benjamins, 271-340.

BEŇUŠ, Stefan (2005) Dynamics and transparency in vowel harmony. PhD dissertation. New York University.

BEŇUŠ, Stefan/Adamantios I. GAFOS (2007) “Articulatory characteristics of Hungarian 'transparent' vowels." Journal of Phonetics 35, 271-300

HALÁCSY, Péter/András KORNAI/László NÉMETH/András RUNG/István SZAKADÁT/Viktor TRÓN (2004) "Creating open language resources for Hungarian." In: Proceedings of Language Resources and Evaluation Conference (LREC04). LREC, 203-210.

HAYES, Bruce/Zsuzsa CZIRÁKY LONDE (2006) "Stochastic phonological knowledge: The case of Hungarian vowel harmony." Phonology 23, 59-104.

HULST, Harry van der/Jeroen van de WEIJER (1995) "Vowel harmony." In: John A. Goldsmith (ed.) 1995. The handbook of phonological theory. Cambridge, MA \& Oxford: Blackwell, 495-534. 
KIPARSKY, Paul/K. PAJUSALU (2003) "Towards a typology of disharmony.” The Linguistic Review 20, 217-241.

REBRUS, Péter/Miklós TÖRKENCZY (2015a) "Monotonicity and the typology of front/back harmony." Theoretical Linguistics 41/1-2, 1-61.

REBRUS, Péter/Miklós TÖRKENCZY (2015b) "The monotonic behaviour of language patterns." Theoretical Linguistics 41/3-4, 241-268.

RINGEN, Catherine/Miklós KONTRA (1989) "Hungarian neutral vowels." Lingua 78, 181-191.

SANDERS, Nathan/K. David HARRISON (2012) Discovering new vowel harmony patterns using a pairwise statistical model. Poster presented at the Twentieth Manchester Phonology Meeting, Manchester, UK, 24-26 May 2012. http://www. swarthmore.edu/SocSci/dharris2/pdfs/sanders-harrison-mfm20-handout.pdf

SIPTÁR, Péter/Miklós TÖRKENCZY (2000) The phonology of Hungarian. Oxford: Oxford University Press.

TÖRKENCZY, Miklós (2011) "Hungarian vowel harmony." In: M. van Oostendorp/C. J. Ewen/E. Hume/K. Rice (eds), The Blackwell Companion to Phonology. Malden, MA \& Oxford: Wiley-Blackwell, 2963-2990.

TÖRKENCZY, Miklós/Péter REBRUS/Péter SZIGETVÁRI (2013) "Harmony that cannot be represented.” In: J. Brandtler/V. Molnár/C. Platzack (eds), Approaches to Hungarian. Papers from the 2011 Lund Conference Volume 13. Amsterdam/Philadelphia: John Benjamins, 229-252.

VAUX, Bert (1998) The Phonology of Armenian. Oxford: Clarendon Press.

VAUX, Bert (2000) "Hungarian vowel harmony. Disharmony and derived transparency in Uyghur vowel harmony." In: M. Hirotani/A. Coetzee/N. Hall/J.-Y. Kim (eds) Proceedings of NELS 30, 671-698.

\section{Summary \\ TYPES AND DEGREES OF VOWEL NEUTRALITY}

This paper argues that neutrality in a harmony system is a gradient property since it is due to a vowel's participation in different patterns that are considered to be indicators of neutral behaviour in harmony. We examine three of these patterns of neutrality (transparency, affixal invariance and antiharmony) and show that a scale of neutrality can be defined on the basis of these patterns (their occurrence and variability) and the neutrality of harmony systems can be characterized with reference to this scale. We describe a tentative quantification of neutrality and then develop an explicit measure of neutrality based on relative word type frequency. This explicit measure is applied to the behaviour of neutral vowels in Hungarian front/back harmony where the different neutral vowels represent different degrees of neutrality in all three neutrality patterns.

Keywords: vowel harmony, neutral vowels, gradience, Hungarian front/back harmony, variation 


\section{Povzetek \\ VRSTE IN STOPNJE SAMOSTALNIŠKE NEVTRALNOSTI}

Članek obravnava nevtralnost $\mathrm{v}$ sistemu harmonije kot stopnjevano lastnost, ki nastane zaradi udeleženosti samoglasnika $\mathrm{v}$ različnih vzorcih, ki so kazalci nevtralnega vedenja $\mathrm{v}$ harmoniji. V prispevku predstavimo tri takšne vzorce nevtralnosti (transparentnost, nespremenljivost pon in antiharmonijo) in pokažemo, da lahko na podlagi teh vzorcev (prek njihove pojavnosti in sprejemljivosti) določimo lestvico nevtralnosti, s katero lahko opišemo nevtralnost sistemov harmonije. Nevtralnost poskušamo tudi kvantificirati in nato razviti eksplicitno merjenje nevtralnosti, ki temelji na relativni pogostnosti tipov besed. Meritev uporabimo za nevtralne samoglasnike v harmoniji madžarskih sprednjih/zadnjih samoglasnikov, pri kateri različni nevtralni samoglasniki predstavljajo različne stopnje nevtralnosti $\mathrm{v}$ vseh treh vzorcih nevtralnosti.

Ključne besede: samoglasniška harmonija, nevtralni samoglasniki, stopnjevanost, harmonija sprednjih/zadnjih samoglasnikov v madžarščini, variacija 